\title{
Understanding transit users in Algiers: Key quality factors at the railway services \\ Rocío de Oña ${ }^{\mathrm{a} *}$, Jose Luis Machado ${ }^{\mathrm{b}}$, Tahar Baouni ${ }^{\mathrm{c}}$, Juan de Oña ${ }^{\mathrm{a}}$
}

${ }^{a}$ TRYSE Research Group, Department of Civil Engineering, University of Granada, ETSI Caminos, Canales y Puertos, c/ Severo Ochoa, s/n, 18071 Granada (Spain)

${ }^{b}$ Department of Civil and Environmental Engineering, University of Washington, 135 More Hall Seattle, WA 98195-2700

${ }^{c}$ Ecole Polytechnique d'Architecture et d'Urbanisme (EPAU) d'Alger, Laboratoire Ville, Urbanisme et Devéloppement Durable , BP 177- 16200 Alger

\begin{abstract}
Algerians citizens most often travel by foot on their daily trips because the lack of a homogeneous offer of public transit and intermodality throughout the city. Furthermore, the private vehicle is experiencing a notable increased use over the last few years. To curb this tendency, the government has launched a metro and a tramway system as key parts of a whole sustainable transport strategy. Guaranteeing the profitability of these modes of transport demands a high quality operation level focused on the users' needs and requirements. While numerous studies have been carried out in developed countries for identifying the essential aspects of different transit modes, this area is still new in developing countries. Then, this paper aims to identify the key quality factors of the railway transit services in Algiers for advising transit authorities and managers towards the most appropriate policy measures. The railway transit services in Algiers consist on three modes of transport: the metro, the tramway (both started into operation in 2011), and a commuter rail system. A Principal Component Analysis combined with a regression model integrates the assessment approach. The results of this research highlight differences among the transit systems analyzed and provide useful insights for the Algiers government and transit authorities.
\end{abstract}


CIT2016 - XII Congreso de Ingeniería del Transporte València, Universitat Politècnica de València, 2016.

DOI: http://dx.doi.org/10.4995/CIT2016.2016.4100

Keywords: Railway transit modes; Developing countries; Quality factors; Users' perceptions; Principal Component Analysis

\section{Introduction}

Developing countries are starting to build rail transit systems as a way of promoting more sustainable mobility in their main cities. For example, in the North of Africa, there are various countries (e.g., Algeria, Morocco) that have started to build metros and light rail transit systems as public transport services represent an essential element for the economic and social development of the nation (de Oña et al., 2016). As public transport gains more presence in these countries, it becomes essential to understand users' needs and requirements with regards to these transit services in order to attract and retain more users and solve the mobility problems found in these countries.

Likewise, in Algiers (Algeria), it exists a problematic situation of the urban transportation network, frequently congested and so called "anarchic" (Safar Zitoun and Tabti Talamali, 2009; Ait Aoudia, 2013). There is a lack of service quality of the bus transit service due to the large number of small private operators and the common handcrafted nature of its services (i.e., lack of timetables and fixed routes). In 2013, there were 4,439 private operators that accounted for $85.2 \%$ of the bus seating capacity offered, whereas two public operators provided the remaining capacity (DTW, 2014). Walking is the mode most frequently used by Algerians, who also walk long distances mostly between 600 to $1.200 \mathrm{~m}(46.7 \%)$ and 1.200 to $2.000 \mathrm{~m}(28.1 \%)$ (BETUR, 2004). The preference for traveling by foot could be due to the lack of a homogeneous offer of public transit and intermodality throughout the city of Algiers (Ait Aoudia, 2013). Furthermore, the private vehicle is experiencing a notable increased use that is exemplified by an $4.77 \%$ average annual increase in car ownership between 2004 and 2008, based on an estimated car ownership of 100 vehicles per 1.000 inhabitants in 2008 (Safar Zitoun and Tabti Talamali, 2009).

A metro and a tramway system started into operation in 2011, as the major structural axes in the city (Ait Aoudia, 2013). This political and financial effort of the government joined to some users-based specific actions for promoting the transit services could provide support to this difficult transport situation. Then, the main objective of this paper is to determine which are the key factors of different transit modes in Algiers from the users' perspective. Particularly, the railways transit systems are analysed through a methodology approach based on principal component analysis and multiple linear regression. PCA reduces a users' perceptions dataset to a more manageable size in order to understand and interpret the structure of the service quality attributes as underlying factors. In addition, multiple lineal regression analysis assesses the relative importance of each factor on users' overall satisfaction. Furthermore, an ad-hoc customer satisfaction survey was designed and carried out to collect the data supporting this research.

Therefore, the paper is structured as follows. Section 2 presents a description about the case study context. Section 3 introduces the data collection procedure, survey structure and sample characteristics. The methodology approach is defined in Section 4. Section 5 presents the analysis of the results and, finally, some brief conclusions are summarized in Section 6.

\section{Description of the case study}

Algiers province registers a population higher than 2.8 million inhabitants. It is estimated that 4.76 million daily trips were generated in 2004 with following modal share: $55.8 \%$ of walking, $28.7 \%$ of public transit, $12.8 \%$ of private vehicle, $2.1 \%$ of taxi and $0.6 \%$ of other modes (BETUR, 2004).

The railway transit service in Algiers consists on a metro, a tramway and a commuter train. The metro service was first operated in November 2011 and was, at that time, the first underground metro service in Maghreb and the second one in North Africa (after the metro service in Cairo, Egypt) (de Oña et al., 2013). Currently, the metro consist of a 1-line underground rail transit of $9.5 \mathrm{~km}$ and 10 stations, and it transported approximately 13 million 
CIT2016 - XII Congreso de Ingeniería del Transporte València, Universitat Politècnica de València, 2016.

DOI: http://dx.doi.org/10.4995/CIT2016.2016.4100

passengers in its first year of operation (de Oña et al., 2013). The tramway service started operations in May 2011 and it currently consists of a $16.2 \mathrm{~km}$ line with 28 stations that transported almost 9 million passengers in 2014 (EMA, 2015). The beginning of the metro itinerary is located in downtown Algiers and goes in the South-East direction across the city. At the metro station Les Fusillés, there is intermodality between one of the four cable cars of the city and the tramway service. The latter serves as a prolongation of the mass transit service in East direction that provides 6 more "communes" (neighborhoods) with access to the city center. Both the metro and tramway service are part of larger projects that consider the extension of the metro network up to three lines and $62 \mathrm{~km}$ (Baouni, 2009), and $23 \mathrm{~km}$ in the case of the tramway network (RATPDEV, 2015). Last, the rail transit system in Algiers is complemented by the commuter rail system, a heavy rail transit service that communicates residential, university and industrial areas of the metropolitan area and the city center, and that transported more than 28.7 millions of passengers in 2012 (SNTF, 2014). The commuter rail network consists of two parts: i) a common tripletrack railway of $10.3 \mathrm{~km}$ and 6 stations that goes southeast across Algiers from the city center until the Harrach train station; ii) the commuter rail continues with a 2-leg railway that communicates the southwestern and eastern parts of the urban agglomeration with double-track railways of $68 \mathrm{~km}$ and $42 \mathrm{~km}$ respectively.

\section{Data collection}

An ad-hoc Customer Satisfaction Survey (CSS) was designed and conducted in the railway transit services described above: the tramway (on-ground light rail transit), the metro (underground light rail transit) and commuter rail (on-ground heavy rail transit). The questionnaire was adapted to each of the three local modes and users' perceptions, trip and socio-demographic characteristics of 1,454 PT users were collected in March 2015. A first version of the CSS was tested and purified by conducting a pilot survey of 347 passengers in November 2014. Both the pilot and the final CSSs were collected by face-to-face interviews and the language chosen to conduct the data collection was French. Although Arabic is the official language in Algiers, French has a significant role in its government, education, culture and media (OIF, 2010). Additionally, the interviewers were able to translate the question to Arabic in a closed form for non-French speaking respondents.

The survey instrument contained from 23 to 26 observed variables (depending on the railway mode) related to different attributes concerning the following service aspects: Availability of the service, Accessibility, Information, Time, Customer Service, Comfort and Safety. These attributes were measured with an 11-point scale (0-lowest quality and 10-highest quality). Moreover, the overall level of satisfaction with the transit service was measured with a 5-point Likert scale (1-lowest level of satisfaction, 5-highest level of satisfaction). Additionally, the survey also contained some questions related to users' travel habits and socio-economic characteristics.

\section{Methodology}

\subsection{Principal Component Analysis}

PCA analyzes interrelationships among a large number of variables and explains these variables in terms of their common underlying factors (Hair et al., 2010). Additionally, this technique allows to make estimates of the factors themselves (factor scores), which then replace the original variables in the subsequent analysis (Hair et al., 2010). Several statistical criteria must be met before a correct application of this analytical technique for ensuring data consistency (Hernandez and Monzon, 2016): sample size, reliability, sampling adequacy, and Bartlett's test sphericity. Field (2009) defined as a proper sample size having at least 10-15 participants per observed variable. Cronbach's alpha is the measure of internal consistency reliability and a value from 0.7 is generally considered to represent an acceptable scale. The index used to measure the sampling adequacy is Kaiser-Meyer-Olkin (KMO) index. The KMO statistic varies between 0 and 1. Hutcheson and Sofroniou (1999) defined values between 0.5-0.7 
as mediocre, values between $0.7-0.8$ as good, values between $0.8-0.9$ as great and values above 0.9 as superb. Finally, significant Bartlett's test indicates if the correlations among the observed variables are sufficiently large to apply a PCA. A criterion of an eigenvalue greater than or equal to 1.0 was used for factor extraction and a VARIMAX orthogonal-rotation method was used as it simplify factor interpretation.

\subsection{Multiple Regression Model}

Multiple regression is a method used to model the linear relationship between a dependent variable and one or more independent variables. The model is estimated by least squares, which yields parameter estimates such that the sum of squares of errors is minimized. The resulting prediction equation is

$$
\mathrm{Yi}=(\mathrm{b} 0+\mathrm{b} 1 \mathrm{Xi1}+\mathrm{b} 2 \mathrm{Xi} 2+\ldots+\text { bn Xin })+\varepsilon \mathrm{i}
$$

Where $\mathrm{Y}$ is the dependent variable, b1 is the coefficient of the first predictor (X1), b2 is the coefficient of the second predictor (X2), bn is the coefficient of the nth predictor $(\mathrm{Xn})$, and $\varepsilon \mathrm{i}$ is the difference between the predicted and the observed value of $\mathrm{Y}$ for the ith observation. In the proposed regression model, the factors extracted from the PCA serve as the independent variables, whereas overall satisfaction serves as the dependent variable. A stepwise procedure was used by adding variables in the regression model if they make a significant contribution to the predictive power of the equation.

\section{Discussion of results}

The factors that define each railway transit mode in Algiers have been extracted through the PCA. Based on the PCA results, attributes that showed a factor loading of 0.4 or higher on the same factor were grouped together (Brons et al., 2009). Four factors were identified at the metro and tramway transit modes, and seven factors were obtained for the train. Table 1, Table 2 and Table 3 show these factors and the main attributes they consist of. The factors that defined the metro are: "Interaction with the service", "Availability", "Comfort" and "Stations". The train is understand with the following factors: "Safety and security", "Comfort at the station", "Comfort on the vehicle", "Accessibility", "Information", "Customer service" and "'Operation". Finally, the tramway is defined with "Comfort", "Availability", "Information" and "Time". The explained cumulative variance of the factors accounted for more than $60 \%$ in the three cases, which can be considered satisfactory (Hair et al., 2010). The size of the sample was proper. Great results were obtained for the KMO index $(>0.8)$ and Bartlett's test also showed highly significant results in all cases $(\mathrm{p}<0.001)$. Additionally, most of the factors showed values of Cronbach alpha around 0.7 or higher, and only two factors obtained slightly lower values. Then, the reliability of the internal consistency of each factor can be considered acceptable.

Moreover, factor weights were estimated with the regression method implemented in SPSS. Factor weights represent the weight each variable should get in order to compute the factor score, that is, the standardized composite measure created for each observation on each factor. Therefore, factor scores were estimated as the weighted average of the scores for the questions it contains (Brons et al., 2009).

Table 1. PCA of Service Quality Attributes for the metro

\begin{tabular}{clllr}
\hline \multicolumn{2}{c}{ Sample size $=446 ;$} & $K M O=0.873 ;$ Barlett's test $=5,563(p<0.000)$; Explained variance=61.187\% & $\begin{array}{c}\text { Factor } \\
\text { loadings }\end{array}$ & $\begin{array}{c}\text { Factor } \\
\text { weights }\end{array}$ \\
\hline SQ1 & & Effectiveness and speed of employees to respond, give information and & \\
INTERACTION & Q12 & deal with user's daily problems (ticket validation problems, etc. $)$ & 0.843 \\
WITH THE & Q14 & Cleanliness of the vehicle & 0.151 \\
SERVICE & S5 & Cleanliness of the stations & 0.145 \\
$\alpha=0.878$ & Q11 & Waiting time on the platform & 0.14 \\
& & & 0.136 \\
& & & 0.807
\end{tabular}




\begin{tabular}{|c|c|c|c|c|}
\hline & Q10 & Speed of the trip & 0.779 & 0.152 \\
\hline & Q20 & Sense of security against theft and aggression in stations and on vehicles & 0.730 & 0.134 \\
\hline & Q7 & Price of the ticket & 0.681 & 0.133 \\
\hline & Q13 & Performance of the Customer Service (offices, web site, phone, etc.) & 0.646 & 0.145 \\
\hline \multirow{7}{*}{$\begin{array}{c}\text { SQ2 } \\
\text { AVAILABILITY } \\
\alpha=0,784\end{array}$} & S3 & Operation of ticket validators at the entrance/exit of stations & 0.763 & 0.265 \\
\hline & $\mathrm{S} 1$ & Operation of elevators, escalators, etc. & 0.714 & 0.206 \\
\hline & Q1 & Operating hours of the service & 0.642 & 0.217 \\
\hline & Q2 & Number of trains per day (frequency of the service) & 0.632 & 0.190 \\
\hline & Q8 & Updated, precise and reliable information on vehicles & 0.610 & 0.200 \\
\hline & Q4 & Regularity of the service (absence of interruptions) & 0.534 & 0.143 \\
\hline & Q6 & Easy access to stations and platforms from the street & 0.506 & 0.143 \\
\hline \multirow{5}{*}{$\begin{array}{c}\text { SQ3 } \\
\text { COMFORT } \\
\alpha=0,815\end{array}$} & Q18 & Appropriate driving & 0.786 & 0.311 \\
\hline & S6 & Lightning in stations & 0.735 & 0.249 \\
\hline & Q16 & Level of comfort on vehicle (seat availability or room standing up) & 0.732 & 0.277 \\
\hline & Q15 & Lightning on vehicles & 0.712 & 0.253 \\
\hline & Q17 & Temperature and ventilation system on vehicle and in stations & 0.574 & 0.212 \\
\hline \multirow{5}{*}{$\begin{array}{c}\text { SQ4 } \\
\text { STATIONS } \\
\alpha=0,617\end{array}$} & Q9 & Updated, precise and reliable information in stations & 0.666 & 0.310 \\
\hline & Q19 & Seat availability in stations and on platforms & 0.658 & 0.277 \\
\hline & & Easy connection with other transportation modes such as taxis, bus, & & \\
\hline & Q5 & tramway, metro, commuter rail, cable car, etc. & 0.658 & 0.278 \\
\hline & Q3 & Proximity of stations to origin/destination & 0.566 & 0.250 \\
\hline
\end{tabular}

Table 2. PCA of Service Quality Attributes for the train

\begin{tabular}{|c|c|c|c|c|}
\hline \multicolumn{3}{|c|}{$\begin{array}{c}\text { TRAIN } \\
\text { Sample size }=495 ; K M O=0.812 ; \text { Barlett's test }=6,043(p<0.000) ; \text { Explained variance }=67.980 \%\end{array}$} & $\begin{array}{r}\begin{array}{c}\text { Factor } \\
\text { loadings }\end{array} \\
0.857\end{array}$ & $\begin{array}{r}\begin{array}{c}\text { Factor } \\
\text { weights }\end{array} \\
0.248\end{array}$ \\
\hline \multirow{3}{*}{$\begin{array}{c}\text { SQ1 } \\
\text { SAFETY AND } \\
\text { SECURITY } \\
\alpha=0,853\end{array}$} & S9 & Safety at stations (protected walkways, signalization, etc.) & 0.818 & 0.226 \\
\hline & Q18 & Appropriate driving & 0.718 & 0.242 \\
\hline & Q10 & Speed of the trip & 0.641 & 0.174 \\
\hline SQ2 & Q19 & Seat availability in stations and on platforms & 0.815 & 0.318 \\
\hline THE STATION & S7 & Services equipment at stations (i.e. toilets, food/drink vending machines) & 0.768 & 0.268 \\
\hline$\alpha=0,833$ & S5 & Cleanliness of the stations & 0.763 & 0.297 \\
\hline SQ3 & Q15 & Lightning on vehicles & 0.856 & 0.353 \\
\hline COMFORT ON & Q14 & Cleanliness of the vehicle & 0.829 & 0.307 \\
\hline THE VEHICLE & Q17 & Temperature and ventilation system on vehicle and in stations & 0.745 & 0.257 \\
\hline$\alpha=0,773$ & Q16 & Level of comfort on vehicle (seat availability or room standing up) & 0.575 & 0.201 \\
\hline \multirow{2}{*}{$\begin{array}{c}\text { SQ4 } \\
\text { ACCESIBILITY } \\
\alpha=0,677\end{array}$} & Q6 & Easy access to satiations and platforms from the street & 0.565 & 0.300 \\
\hline & Q4 & Regularity of the service (absence of interruptions) & 0.533 & 0.212 \\
\hline SQ5 & Q8 & Updated, precise and reliable information on vehicles & 0.858 & 0.488 \\
\hline \multirow{2}{*}{$\begin{array}{c}\text { INFORMATION } \\
\alpha=0,684 \\
\end{array}$} & Q9 & Updated, precise and reliable information in stations & 0.804 & 0.450 \\
\hline & S4 & Punctuality & 0.425 & 0.185 \\
\hline SQ6 & & Effectiveness and speed of employees to respond, give information and & & \\
\hline CUSTOMER & Q12 & deal with user's daily problems (ticket validation problems, etc.) & 0.779 & 0.437 \\
\hline SERVICE & Q13 & Performance of the Customer Service (offices, web site, phone,etc.) & 0.778 & 0.430 \\
\hline$\alpha=0,681$ & Q11 & Waiting time on the platform & 0.491 & 0.278 \\
\hline
\end{tabular}


CIT2016 - XII Congreso de Ingeniería del Transporte València, Universitat Politècnica de València, 2016. DOI: http://dx.doi.org/10.4995/CIT2016.2016.4100

\begin{tabular}{clll}
\hline SQ7 OPERATION & Q2 & Operating hours of the service & 0.770 \\
$\alpha=0,609$ & Q1 & Number of trains per day (frequency of the service) & 0.500 \\
\hline
\end{tabular}

Table 3. PCA of Service Quality Attributes for the tramway

\begin{tabular}{|c|c|c|c|c|}
\hline \multicolumn{3}{|c|}{$\begin{array}{c}\text { TRAMWAY } \\
\text { Sample size }=513 ; \mathrm{KMO}=0.800 ; \text { Barlett's test }=5,113(p<0.000) ; \text { Explained variance }=64.460 \%\end{array}$} & \multirow{2}{*}{$\begin{array}{r}\begin{array}{c}\text { Factor } \\
\text { loadings }\end{array} \\
0.813\end{array}$} & \multirow{2}{*}{$\begin{array}{r}\begin{array}{c}\text { Factor } \\
\text { weights }\end{array} \\
0.224\end{array}$} \\
\hline \multirow{6}{*}{$\begin{array}{c}\text { SQ1 } \\
\text { SAFETY \& } \\
\text { SECURITY/ } \\
\text { COMFORT } \\
\alpha=0.804\end{array}$} & Q17 & Temperature and ventilation system on vehicle and in stations & & \\
\hline & Q14 & Cleanliness of the vehicle & 0.768 & 0.206 \\
\hline & S8 & Sense of security against accidents while traveling & 0.700 & 0.169 \\
\hline & Q19 & Seat availability in stations and on platforms & 0.580 & 0.271 \\
\hline & Q20 & Sense of security against theft and aggression in stations and on vehicles & 0.580 & 0.185 \\
\hline & S3 & Operation of ticket validators at the entrance/exit of stations & 0.494 & 0.074 \\
\hline \multirow{5}{*}{$\begin{array}{c}\text { SQ2 } \\
\text { AVAILABILITY } \\
\alpha=0.712\end{array}$} & Q1 & Operating hours of the service & 0.698 & 0.224 \\
\hline & Q2 & Number of trains per day (frequency of the service) & 0.695 & 0.281 \\
\hline & Q6 & Easy access to stations and platforms from the street & 0.624 & 0.222 \\
\hline & Q4 & Regularity of the service (absence of interruptions) & 0.581 & 0.202 \\
\hline & Q3 & Proximity of stations to origin/destination & 0.567 & 0.236 \\
\hline \multirow{3}{*}{$\begin{array}{c}\text { SQ4 } \\
\text { TIME } \\
\alpha=0.664\end{array}$} & Q11 & Waiting time on the platform & 0.816 & 0.358 \\
\hline & Q10 & Speed of the trip & 0.736 & 0.331 \\
\hline & Q5 & $\begin{array}{l}\text { Easy connection with other transportation modes such as taxis, bus, } \\
\text { tramway, metro, commuter rail, cable car, etc. }\end{array}$ & 0.531 & 0.237 \\
\hline
\end{tabular}

Subsequently, a multiple linear regression model was calibrated for each transit mode in order to derive which are the key factors of each railway system. All coefficients of determination $\mathrm{R}^{2}$ were statistically significant at 0.001 , and the models explain around a $30 \%$ the variability in the overall satisfaction measure in all cases. This is a fairly typical value for this kind of application (Weinstein, 2000), although it is important to note that two-thirds of the variability is not explained.

Certainly, not all the factors included in the regression models are important for users' overall satisfaction. As shown in Table 4, some factors are more significant that other in understanding this term. The factors that do not show a significant influence $(p>0.10)$ in the overall satisfaction have not been included in the model. In the case of the metro, "Interaction" plays the most important role $(\beta=0.463)$, followed by "Comfort" and "Availability". The factor "Stations" does not exert a significant influence on the users' satisfaction. For the train, the regression result revealed that users overall satisfaction was determined mainly by "Safety and security" $(\beta=0.453)$ and "Comfort on the vehicle" ( $\beta=0.262)$. Other aspects such as "Information", "Accessibility" and "Comfort at the station" also obtained an important effect on users' satisfaction. Conversely, users' satisfaction was not associated with "Customer service" and "Operation". Finally, with regards to the relative effects found on the tramway service, the $\beta$ coefficients indicated that "Time" and "Safety and Security/Comfort" represented the key aspects of this mode of transport. 
Table 4. Stepwise multiple regression analysis results for the metro, train and tramway

\begin{tabular}{|c|c|c|c|c|c|}
\hline Predictors & Unstd. Coef. $B$ & Std. Error & Std. Coef $B$ & $\mathbf{t}$ & sig. \\
\hline METRO & \multicolumn{5}{|c|}{$F=63.124 * * *, R^{2}=0.300$, Adjusted $R^{2}=0.295$} \\
\hline (Constant) & 1.442 & 0.306 & & $4.719 * * *$ & 0.000 \\
\hline SQ1. INTERACTION & 0.214 & 0.019 & 0.463 & $11.089 * * *$ & 0.000 \\
\hline SQ2.AVAILABILITY & 0.065 & 0.034 & 0.087 & 1.928 & 0.055 \\
\hline SQ3. COMFORT & 0.141 & 0.035 & 0.185 & $4.009 * * *$ & 0.000 \\
\hline TRAIN & \multicolumn{5}{|c|}{$F=67.664 * * *, R^{2}=0.400$, Adjusted $R^{2}=0.394$} \\
\hline (Constant) & -0.127 & 0.229 & & -0.556 & 0.578 \\
\hline SQ1. SAFETY AND SECURITY & 0.213 & 0.017 & 0.453 & $12.933 * * *$ & 0.000 \\
\hline SQ2. COMFORT AT THE STATION & 0.052 & 0.022 & 0.096 & 2.392 & 0.017 \\
\hline SQ3. COMFORT ON THE VEHICLE & 0.151 & 0.021 & 0.262 & $7.006 * * *$ & 0.000 \\
\hline SQ4. ACCESIBILITY & 0.115 & 0.029 & 0.154 & $4.006 * * *$ & 0.000 \\
\hline SQ5. INFORMATION & 0.083 & 0.019 & 0.163 & $4.451 * * *$ & 0.000 \\
\hline TRAMWAY & \multicolumn{5}{|c|}{$F=102.908 * * *, R^{2}=0.386$, Adjusted $R^{2}=0.382$} \\
\hline (Constant) & 0.661 & 0.237 & & 2.789 & 0.005 \\
\hline SQ1. SAFETY AND SECURITY/COMFORT & 0.213 & 0.019 & 0.395 & $11.125 * * *$ & 0.000 \\
\hline SQ3. INFORMATION & -0.107 & 0.014 & -0.272 & $-7.452 * * *$ & 0.000 \\
\hline SQ4. TIME & 0.292 & 0.023 & 0.453 & $12.451 * * *$ & 0.000 \\
\hline
\end{tabular}

\section{Conclusions}

The main aim of this paper was to identify which were the key factors of the railways transit services in Algiers from the users' perspective. In addition, the structure of the service quality attributes as underlying factors was obtained for each mode of transport, allowing transport authorities and transport managers to understand how users conceptualize in their mind each transit system. Multiple linear regressions models were calibrated for determining the relative influence of each service quality factor on users' overall satisfaction. While metro service's satisfaction is more determined by the "Interaction", "Safety and security" and "Time" play the most important role in the train and the tramway respectively. This analytical assessment permits to formulate specific users-based strategic actions to attract and retain new users and support the government sustainable transport initiatives.

\section{Acknowledgements}

The authors would like to thank the Spanish Initiatives of Development Cooperation Center at the University of Granada (CICODE) that funded the international university cooperation project C13P11_2014. The authors also acknowledge the students from the VUDD laboratory (EPAU) for their collaboration on the data collection, the RATP El Djazaiir, SETRAM and SNTF for their cooperation during the surveys. 
CIT2016 - XII Congreso de Ingeniería del Transporte València, Universitat Politècnica de València, 2016.

DOI: http://dx.doi.org/10.4995/CIT2016.2016.4100

\section{References}

Ait Aoudia, O. (2013) Maitriser et revivre la ville: le metro d'Alger.In, No. Magistère d'Aménagement et d'Urbanisme, Université Panthéon Sorbonne, Paris, pp. 129.

Baouni, T. (2009) Le transport collectif urbain dans la ville d'Alger: un service public à la recherche de son adaptation. Vies de Villes, 12, pp. 3437.

Betur (2004). Enquête Ménages sur les déplacements dans l'agglomération d'Alger.In, Ministère des Transports, Bureau d'Etudes des Transports Urbains, Algiers.

Brons, M., M. Givoni, and P. Rietveld. (2009) Access to railway stations and its potential in increasing rail use. Transportation Research Part A: Policy and Practice, 43 (2), pp. 136-149.

Chabane, L. (2013) From deregulation to re-regulation of travellers urban transport in Algeria, what is the private operator's position in the urban area of Algiers? Presented at 13th World Conference on Transport Research, Rio de Janeiro

De Oña, J., T. Baouni, and R. De Oña (2013). The metro in Algiers: user profile and quality of service. WIT Transactions on the Built Environment, 130, pp. 11.

De Oña, J., Baouni, T., Machado, J.L., Berchache, R., Bajour, M. (2016) Railway transit services in Algiers: priority improvement actions based on users perceptions. Presented at the 95th Annual Meeting Transportation Research Board, Washington D.C

DTW (2014) Répartition du parc autobus par opérateur.In, Direction des Transports de la Wilaya d'Alger (unpublished data)

EMA (2014). Frquentation des tramways d'Alger, d'Oran et de Constantine pour les annes 2013 et 2014. Entreprise Metro D'Alger. http://www.metroalger-dz.com/fr/statistiques.php.

Field, A.P. (2009). Discovering statistics using SPSS: (and sex, drugs and rock'n'roll) (third edition). SAGE.

Hair, J. F., W. C. Black, B. J. Babin, and R. E. Anderson (2010). Multivariate Data Analysis: A Global Perspective. Prentice Hall, New Jersey.

Hernandez, S. and Monzon, A. (2016) Key factors for defining an efficient urban transport interchange: Users' perceptions. Cities, 50, pp. 158167

Hutcheson, G.D., and Sofroniou, N. (1999). The multivariate social scientist: introductory statistics using generalized linear models (1 edition ). London: Thousand Oaks, Calif: SAGE Publications Ltd

OIF (2010). La langue française dans le monde 2010.In, Observatoire International de la Francophonie, Paris, 2010

RATPDEV (2015). SETRAM. Régie Autonome des Transports Parisiens Développement. https://www.ratpdev.com/en/setram.

Safar Zitoun, M., and A. Tabti Talamali (2009). Plan Bleu, données de l'étude de cas La mobilité urbaine dans l'agglomération d'Alger: évolutions et perspectives.In, World Bank Institute, Alger, pp. 108.

SNTF (2014). Données de base concernant le réseau de chemin de fer à Alger et sa banlieue.In, Société Nationale des Transport Ferroviaires (unpublished data).

Weinstein, A. (2000). Customer satisfaction among transit riders. How customer rank the relative importance of various service attributes. Transportation Research Record, 1735, pp. 123-132 